\title{
Environmental Impacts of Hydrogen Production by Hydrothermal Gasification of a Real Biowaste
}

\author{
Sevgihan Yildiz Bircan, Kozo Matsumoto and Kuniyuki Kitagawa
}

Additional information is available at the end of the chapter

http://dx.doi.org/10.5772/50329

\section{Introduction}

Energy consumption is increasing regularly with increasing human population [1]. Finite resources of fossil fuels [2], security of other energy sources (especially nuclear energy), and concerns over greenhouse gases produced by combustion of fossil fuels have all motivated the search for renewable energy sources [3]. Energy from biomass could reduce the increase of carbon dioxide in the atmosphere and provide $14 \%$ of the world's energy needs $[4,5]$. Also biomass gasification through the hydrothermal process has the added advantage of disposing of wastes [6]. Therefore, biomass has been selected for generation of energy by using hydrothermal gasification.

Hydrogen gas is anticipated as a fuel for clean power systems such as fuel cells. Many techniques have been reported for producing hydrogen gas [7, 8]. Hydrothermal gasification in sub or supercritical water has also been studied as a promising process for hydrogen production. The fluid can dissolve and decompose organic compounds [9]. Hydrothermal gasification is carried out at a relatively low temperature (about $400{ }^{\circ} \mathrm{C}$ ) and occurs rapidly, compared with fermentation processes $[10,11]$. Furthermore, hydrothermal gasification is carried out in supercritical fluid water, so this method is applicable to wet biomass samples without the necessity for a drying process, while the conventional thermal gasification needs excessive energy to dry wet biomass before it is gasified $[4,9,12]$. This process is therefore more suitable for biowastes with high water content, such as food wastes and animal dungs, than the conventional thermal gasification process that requires additional energy to overcome the latent heat of water.

There have been numerous studies related to the hydrothermal gasification process, and conducted for wide range of materials. Morimoto et al. [13] of Kyoto University studied hydrothermal gasification process of brown coal. Antal et al. [14] reported the gasification of cornstarch and wood dust. Yoshida et al. [15] studied supercritical water gasification of 
cellulose, hemi-cellulose, and lignin. However, this process has not been studied for animal waste, because animal wastes were thought to have the potential for environmental pollution $[16,17,18]$.

Toxic compounds might be produced through the hydrothermal gasification of real biomass. Some chlorinated organic compounds are very toxic and can cause serious damage to the human body even with exposures of trace amounts. This study has also made a determination of resulting dioxins as these are among the most toxic substances.

This method would not be an optimum solution for disposing biowaste. However, hydrogen production by hydrothermal gasification of biowaste appears to be a promising source for the predicted hydrogen fuel production needs [19].

\subsection{Hydrothermal gasification}

Hydrothermal processing describes the thermal treatment of wet biomass at elevated pressures to produce carbohydrate, liquid hydrocarbons, or gaseous products depending upon the reaction conditions [20].

The processing pressure must be increased as the reaction temperature increases to prevent boiling of water in the wet biomass. At temperatures around $100{ }^{\circ} \mathrm{C}$, extraction of high-value plant chemicals such as reins, fats, phenolics, and phytosterols is possible. At $200{ }^{\circ} \mathrm{C}$ and 2 $\mathrm{MPa}$, fibrous biomass undergoes a fractionation process to yield cellulose, lignin, and hemicellulose degradation products such as furfural. Further hydrothermal processing can hydrolyze the cellulose to glucose. At $300-350{ }^{\circ} \mathrm{C}$ and $12.2-18.2 \mathrm{MPa}$, biomass undergoes more extensive chemical reactions, yielding a hydrocarbon-rich liquid known as biocrude. At $600-650{ }^{\circ} \mathrm{C}$ and $30.4 \mathrm{MPa}$ the main products are gases, including a significant fraction of methane [20].

Hydrothermal pyrolysis is also known as hydrothermal liquefaction. Hydrothermal pyrolysis is a feasible method for waste treatment and conversion of wastes into liquid bioproducts such as bio-oil. Hydrothermal liquefaction of biomass is a depolymerization process to break the solid organic compounds into smaller fragments [21].

In hydrothermal liquefaction, water simultaneously acts as a reactant and so this process is significantly different from pyrolysis [22].

Biomass can be thermally processed through either gasification or pyrolysis to produce hydrogen and other fuels. In general, the main gaseous products from the pyrolysis of biomass are $\mathrm{H}_{2}, \mathrm{CO}_{2}, \mathrm{CO}$, and hydrocarbon gases, whereas the main gaseous products from the gasification of biomass are $\mathrm{H}_{2}, \mathrm{CO}_{2}, \mathrm{CO}$, and $\mathrm{N}_{2}$ [23].

Hydrothermal biomass gasification benefits from the special properties of near- and supercritical water as the solvent and its presence as the reaction partner. Relatively fast hydrolysis of biomass in sub and supercritical water leads to a rapid degradation of the polymeric structure of biomass [9]. 


\subsection{Super critical water}

A supercritical fluid (SCF) is any substances at a temperature and pressure above the critical point. Above the critical temperature of a substance, the pure, gaseous component cannot be liquefied regardless of the pressure applied. The critical pressure is the vapor pressure of the gas at the critical temperature. In the supercritical environment only one phase exists. The fluid, as it is termed, is neither a gas nor a liquid and is best described as intermediate to the two extremes. This phase retains solvent power approximating liquids as well as the transport properties common to gases.

At conditions around the critical point water has several valuable properties. Among them are low viscosity and high solubility of organic substances, making subcritical water an excellent medium for fast, homogeneous and efficient reactions. Supercritical water gasification is a promising technology for gasifying biomass with high moisture content [24]. Use of water as a reaction medium obviates the need to dry the feedstock and allows a fast reaction rate [25]. However corrosion in the subcritical water is a key issue [22].

There are two approaches to biomass gasification in supercritical water. The first: lowtemperature catalytic gasification employs a reaction temperature ranging from 350 to 600 ${ }^{\circ} \mathrm{C}$ (above $22.05 \mathrm{MPa}$ ) and gasifies the reaction material with the aid of metal catalysts. The second: high-temperature supercritical water gasification employs reaction temperatures ranging from 500 to $750{ }^{\circ} \mathrm{C}$ (above $25 \mathrm{MPa}$ ), either without a catalyst or with non-metallic catalysts [10].

For the disposal of chicken manure, the advantages of hydrothermal gasification method are summarized in the Figure 1 below, which also shows some disadvantages of other methods.

\subsection{Experimental equipment}

The experimental setup was developed in this work for hydrothermal gasification. A stainless steel tube of SUS 316 of $1 / 2$ inch in O.D., $12 \mathrm{~cm}$ in length is used as the reactor. One side of the reactor was sealed with a connector (Swagelok Co.) and the other side was connected with a $1 / 2$ to $1 / 8$ inch reducing union to which the Tee was connected. The strain amplifier for pressure measurement (Kyowa-Dengyo, Co., Japan) was connected to the one side of the Tee, and the stop valve was to the other side. A gas chromatograph oven (Hewlett Packard, 5890 GC) was used for heating the reactor at a programmed temperature $[26,27]$.

\subsection{Reagents}

Chicken manure (G.I. Ltd., Japan) containing 9\% phosphorus was selected as a real biomass waste.

As a model sample containing phosphorus element, O-Phospho-DL-serine (Wako Chemical Co. Ltd, Japan) was used. O-Phospho-DL-serine, as the name implies, has a serine, which is an amino acid with the formula $\mathrm{HO}_{2} \mathrm{CCH}\left(\mathrm{NH}_{2}\right) \mathrm{CH}_{2} \mathrm{OH}$. It is one of the proteinogenic amino 
acids. By virtue of the hydroxyl group, serine is classified as a polar amino acid. O-PhosphoDL-serine consists with phosphorylation of serine. Aspartate, glutamate, proline and serine are abundant amino acids in chicken manure [28]. Some of the constituent amino acids were found in a range from $24.7 \%$ (for valine) to $76.4 \%$ (for serine) in poultry manure [29]. Ophospho-DL-serine also contains the $\mathrm{P}$ atom in the molecule. Therefore it was chosen as the test sample.

$\mathrm{Ca}(\mathrm{OH})_{2}$ used as an additive was purchased from Wako Chemical Co. Ltd, Japan.

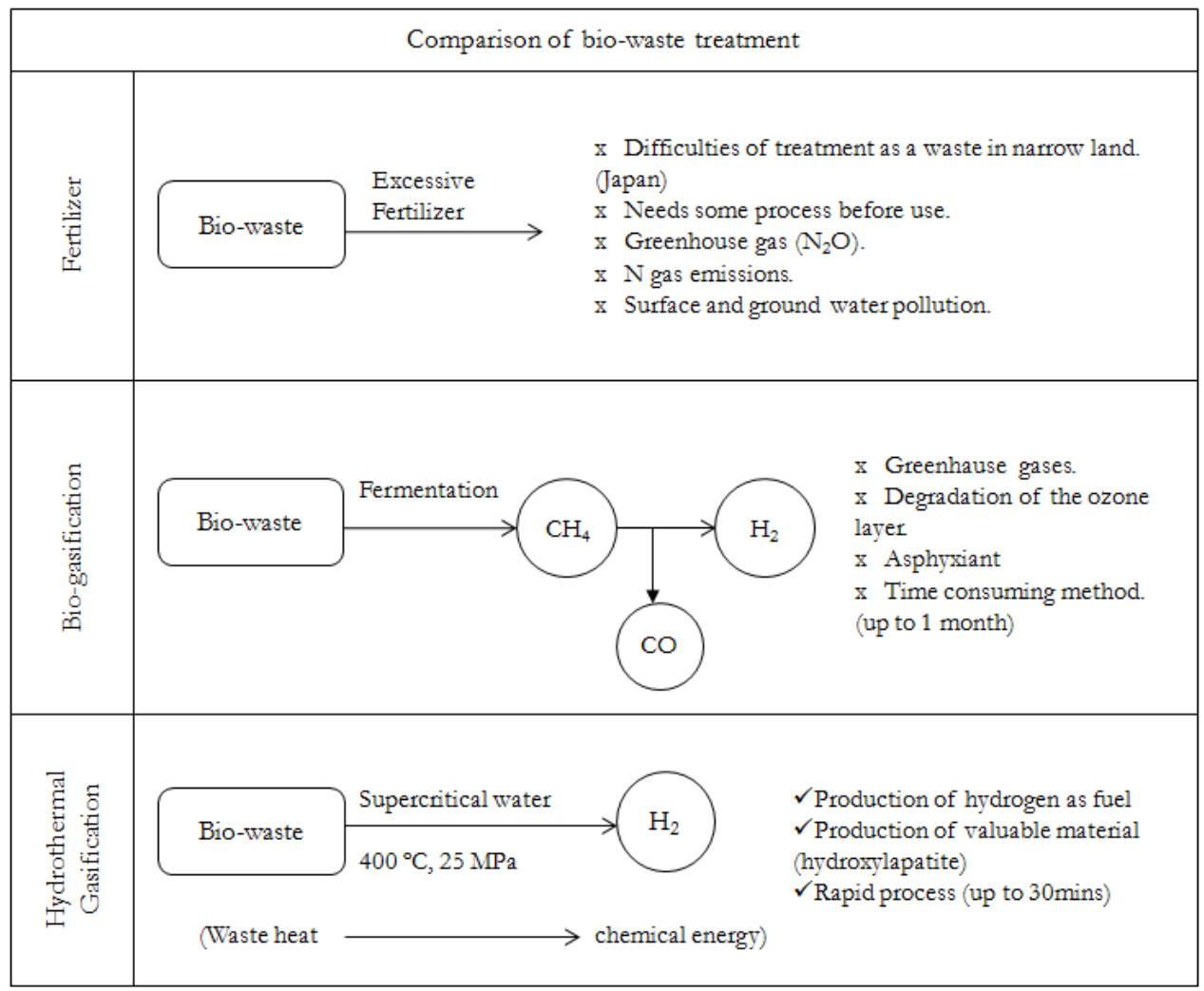

Figure 1. Diagram of comparison for bio-waste treatment.

\subsection{Procedure for hydrothermal gasification}

The biomass sample (chicken manure or O-Phospho-DL-serine) was weighed (about 100 $\mathrm{mg}$ ) and put into the reactor. Additionally, the alkaline additive $\mathrm{Ca}(\mathrm{OH})_{2}$ was weighed and added into the reactor (without $\mathrm{Ca}(\mathrm{OH})_{2}$, with $2 \mathrm{mmol}$ and $\left.3 \mathrm{mmol} \mathrm{Ca}(\mathrm{OH})_{2}\right)$. Then $5 \mathrm{ml}$ water was added. $\mathrm{N}_{2}$ gas was introduced to purge the residual $\mathrm{O}_{2}$ gas in the reactor. After the reactor was connected to the reducing unit with the pressure gauge and the stop valve, the reactor was placed in the oven. Then the oven was heated to $400^{\circ} \mathrm{C}$ at $0.025^{\circ} \mathrm{C} \mathrm{min}^{-1}$. The 
reactor was kept at $400^{\circ} \mathrm{C}$ for 40 minutes to complete the hydrothermal reaction under a pressure of 26 27 MPa. Subsequently, the oven was cooled down to room temperature and the components generated were analyzed $[26,27]$.

The experimental procedures are illustrated in Fig. 2 and comprised three main stages; sample preparation, hydrothermal gasification, and analysis of the compounds produced.

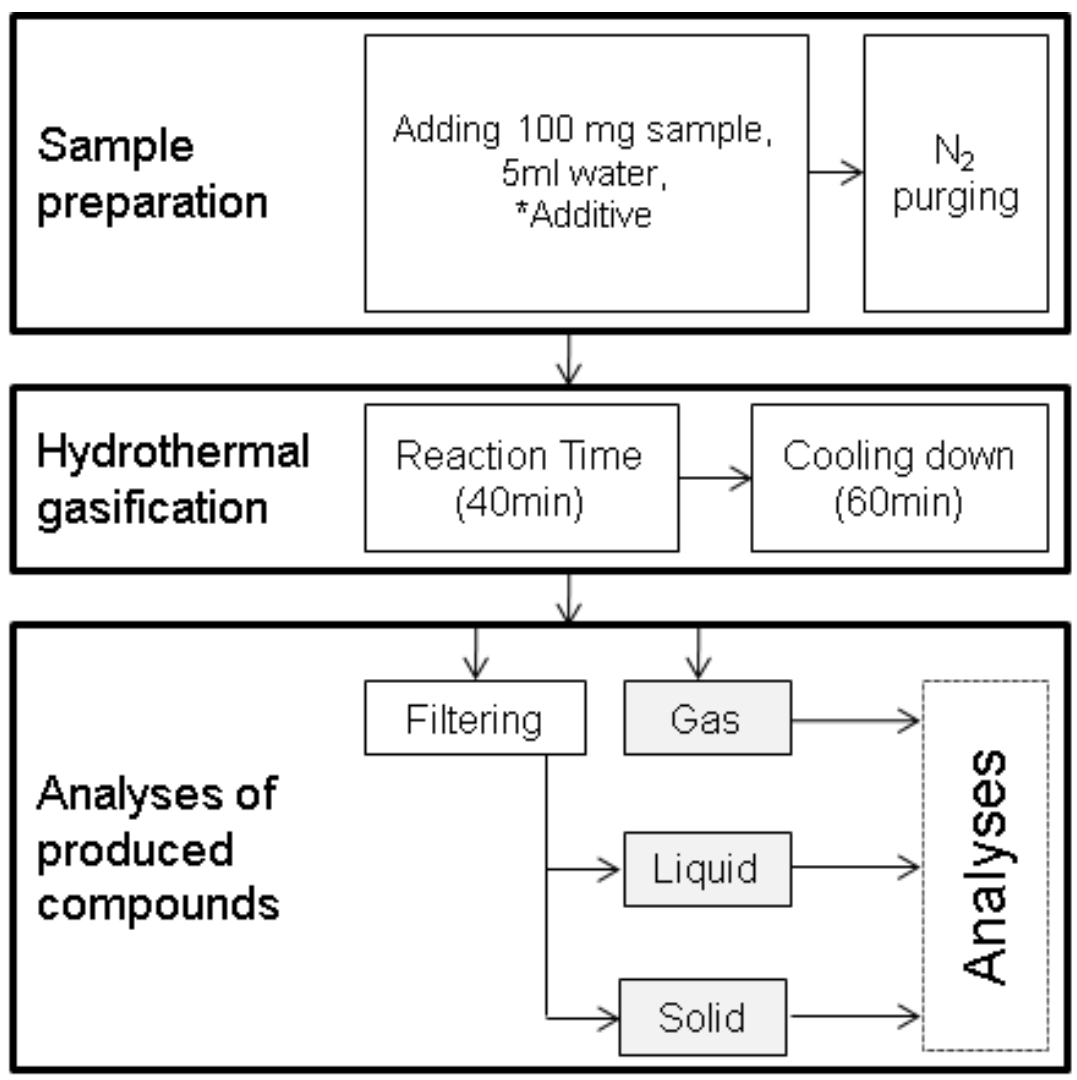

Figure 2. Experimental procedures of hydrothermal gasification

\subsection{Analytical equipment}

GC-TCD (Gas Chromatography - Thermal Conductivity Detector)

A 5A Shimadzu Gas Chromatograph (GC) of equipped with a thermal conductivity detector (TCD) was used for the analysis of chemical species in the gas phase.

\section{IC (Ion Chromatography)}

A Shimadzu (HIC-SP) Ion Chromatograph (IC) was used for the analysis of ionic species in the liquid phase. 


\section{GC/MS (Gas Chromatography/Mass Spectrometry)}

More than $100 \mathrm{ml}$ of the liquid sample was required for the determination of dioxins by GC/MS. The reaction procedure was repeated 27 to 30 times for each sample.

Dioxin analysis was performed on the resulting liquid and solid samples using a gas chromatograph combined with a mass spectrometer. An Agilent model 6890-GC interfaced with a JMS-700D double focus MS (JEOL, Japan) was used for the analysis [27].

\section{Generation of hydrogen gas}

For effective production of hydrogen gas and reduction of the formation of pollutants, optimum conditions for hydrothermal gasification of biowaste were examined under various experimental conditions by using O-phospho-DL-serine as a test sample. Next, chicken manure was used as a real biomass waste sample for the production of hydrogen gas by the hydrothermal gasification and for the suppression of the pollutants.

Additives were used to enhance the reaction rate of the hydrothermal gasification in sub or supercritical water at low reaction temperature [10]. The study also looked at whether the addition of catalysts could also enhance the hydrogen yield [30].

Several additives were used in earlier studies. The effects of the various alkaline metals on the amounts of generated gases have been reported [31]. When $\mathrm{Ca}(\mathrm{OH})_{2}$ was used, only hydrogen gas was produced without production of other gases. This would be explained by the following Equations 1 and 2.

$$
\begin{gathered}
\mathrm{H}_{2} \mathrm{O}+\mathrm{CO}---\mathrm{CO}_{2}+\mathrm{H}_{2} \\
\mathrm{Ca}(\mathrm{OH})_{2}+\mathrm{CO}_{2} \rightarrow \mathrm{CaCO}_{3}+\mathrm{H}_{2} \mathrm{O}
\end{gathered}
$$

The effects of the addition of various kinds of alkaline metals on the amounts of phosphate ion were also studied. The addition of $\mathrm{Na}_{2} \mathrm{CO}_{3}$ or $\mathrm{K}_{2} \mathrm{CO}_{3}$ was found to have no suppression effect on the production of phosphate ions in the liquid phase. However, when $\mathrm{Ca}(\mathrm{OH})_{2}$ was added, no phosphate ions were detected. From these experimental results [31], it can be concluded that reasonable alkaline element compound, $\mathrm{Ca}(\mathrm{OH})_{2}$ was a suitable additive because it could suppress the production of heteroatom pollutants in the gas phase and enhance the hydrogen yield [26].

\subsection{Gas phase}

The effects of the amounts of additive and temperature on the yield of gases generated were studied.

Without the additive, the main produced gas is $\mathrm{CO}$, while hydrogen gas is also generated. $0.1943 \mathrm{mmol} \mathrm{H}_{2}, 0.2617 \mathrm{mmol} \mathrm{CO}, 0.0244 \mathrm{mmol} \mathrm{CO}_{2}, 0.0024 \mathrm{mmol} \mathrm{CH}_{4}$, and $0.0088 \mathrm{mmol}$ $\mathrm{C}_{2} \mathrm{H}_{4}, 0.0010 \mathrm{C}_{2} \mathrm{H}_{6}$ were detected [26]. 
With the addition of $2 \mathrm{mmol} \mathrm{Ca}(\mathrm{OH})_{2}$, the yield of $\mathrm{CO}, \mathrm{CO}_{2}$ and $\mathrm{C}_{2} \mathrm{H}_{4}$ gases were suppressed. However, the generation of hydrogen gas was decreased in yield. $0.1459 \mathrm{mmol}$ $\mathrm{H}_{2}, 0.0019 \mathrm{mmol} \mathrm{CO}, 0.0009 \mathrm{mmol} \mathrm{CO}, 0.0039 \mathrm{mmol} \mathrm{CH}_{4}$, and $0.0019 \mathrm{mmol} \mathrm{C}_{2} \mathrm{H}_{4}, 0.0003$ $\mathrm{C}_{2} \mathrm{H}_{6}$ were detected [26].

With the addition of $3 \mathrm{mmol} \mathrm{Ca}(\mathrm{OH})_{2}$, the main gas is hydrogen gas, while other gases were hardly detected. With addition of $3 \mathrm{mmol} \mathrm{Ca}(\mathrm{OH})_{2}$, the main gas is hydrogen gas. Generation of hydrogen gas increases with an increase of gasification temperature. 0.2007

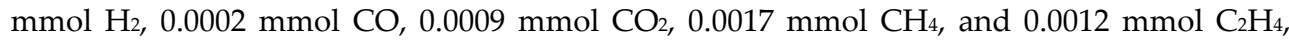
$0.0016 \mathrm{C}_{2} \mathrm{H}_{6}$ were detected [26].

The enhancement of $\mathrm{H}_{2}$ yield by adding alkali was due to water-gas shift reactions. These results indicate that the most suitable conditions for obtaining pure hydrogen gas from the hydrothermal reaction of the model sample, O-Phospho-DL-serine, are as follows: $3 \mathrm{mmol}$ of additive $\mathrm{Ca}(\mathrm{OH})_{2}$, reaction temperature at $400^{\circ} \mathrm{C}$, and pressure of $22 \mathrm{MPa}$ (super critical state).

\subsection{Liquid phase}

The effects of the added amount of $\mathrm{Ca}(\mathrm{OH})_{2}$ on the yield of phosphate ion dissolved in the liquid phase through the hydrothermal reaction under the supercritical conditions at $400^{\circ} \mathrm{C}$ were also studied. When no additive was used, the yield of phosphate ion in the liquid phase found was $93.3 \%$ of the $\mathrm{P}$ in the original sample. However, the addition of $2 \mathrm{mmol} \mathrm{Ca}(\mathrm{OH})_{2}$ resulted in the suppression of the formation of phosphate ion in the liquid phase. When $3 \mathrm{mmol}$ of $\mathrm{Ca}(\mathrm{OH})_{2}$ was added, the generation of phosphate ion was further decreased to $5.6 \%$. Phosphorus containing compounds were barely detectable in the liquid phase. Phosphorus in the sample would be converted and precipitated as solid compounds (Figure 3).

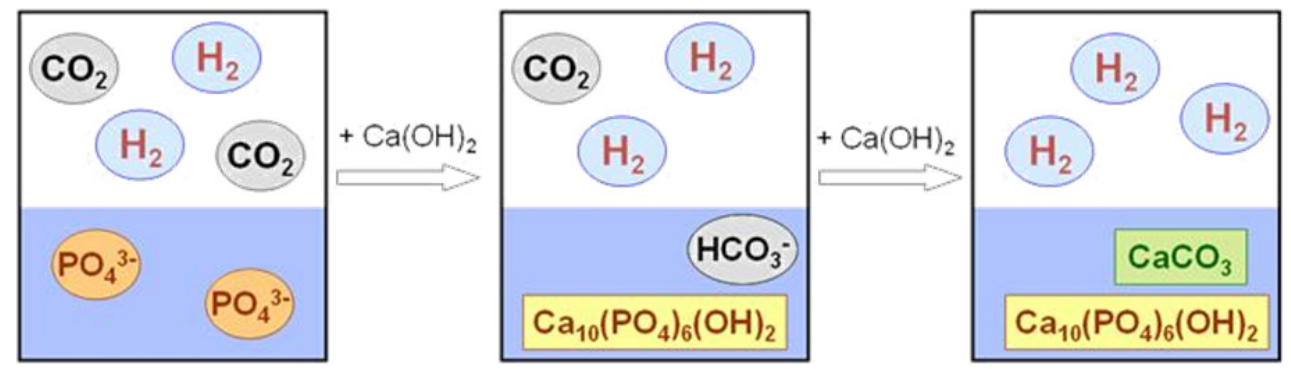

Figure 3. Estimation of phosphorus conversion.

\subsection{Hydrothermal gasification of chicken manure}

Chicken manure, which contains phosphorus, was selected as a real biowaste for the production of hydrogen gas and suppressing formation of pollutants by the hydrothermal reaction. Various reaction conditions were investigated for suitable conditions. The same optimum conditions were obtained as those of the hydrothermal reaction of the model test compound, O-Phospho-DL-serine. With the same conditions of $3 \mathrm{mmol} \mathrm{Ca}(\mathrm{OH})_{2}$ and $400^{\circ} \mathrm{C}$, 
hydrogen gas was mainly produced in the gas phase. $0.1122 \mathrm{mmol} \mathrm{H}_{2}, 0.0044 \mathrm{mmol} \mathrm{CO}$, $0.2088 \mathrm{mmol} \mathrm{CO}_{2}, 0.0025 \mathrm{mmol} \mathrm{CH}_{4}$, and $0.0114 \mathrm{mmol} \mathrm{C}_{2} \mathrm{H}_{4}, 0.0014 \mathrm{C}_{2} \mathrm{H}_{6}$ were detected. $\mathrm{H}_{2}$ yields were increased and other gasses were suppressed by using the additive, especially in the case of $\mathrm{CO}_{2}$, which was suppressed very effectively. It was concluded that the enhancement of $\mathrm{H}_{2}$ yield by adding the alkali was due to the water-gas shift reactions (Equations 3 and 4). Equation (5) shows the production of $\mathrm{CaCO}_{3}$ after hydrothermal gasification by adding $\mathrm{Ca}(\mathrm{OH})_{2}[26]$.

$$
\begin{gathered}
\text { Org. } \mathrm{C}+\mathrm{H}_{2} \mathrm{O} \rightarrow \mathrm{CO}+\mathrm{H}_{2} \\
\mathrm{H}_{2} \mathrm{O}+\mathrm{CO} \rightarrow \mathrm{CO}_{2}+\mathrm{H}_{2} \\
\mathrm{CO}_{2}+\mathrm{Ca}(\mathrm{OH})_{2} \rightarrow \mathrm{CaCO}_{3}+\mathrm{H}_{2} \mathrm{O}
\end{gathered}
$$

Additionally, phosphate ion was hardly detected in the liquid phase as in case of the model sample. The phosphorus compounds in the real sample are decomposed and new compounds would be produced and precipitated in the solid phase by the hydrothermal reaction. From these results the following equation is obtained (Equation 6). When the sample includes phosphorus, the $\mathrm{P}$ element would be converted into $\mathrm{PO}_{4}^{3-}$ by the hydrothermal reaction [26]. The ion, $\mathrm{PO}^{3-}$, would react with $\mathrm{Ca}^{2-}$ ion and some insoluble compound would be produced.

$$
\mathrm{P}(\text { in a Sample })+\mathrm{H}_{2} \mathrm{O} \rightarrow \mathrm{PO}_{4}^{3-}
$$

When $\mathrm{Ca}(\mathrm{OH})_{2}$ was used as the additive, the main produced gas was hydrogen gas, and the generation of $\mathrm{CO}_{2}$ gas was suppressed efficiently. Additionally, calcium ion easily reacts with heteroatoms, and would form insoluble solid material in water. The cost of $\mathrm{Ca}(\mathrm{OH})_{2}$ is less expensive than other additives. To treat a large amount of bio-wastes, reasonable reagents are more preferable. $\mathrm{Ca}(\mathrm{OH})_{2}$ was decided to use as the additive for understanding the reaction mechanisms for disposal of hetero-atom containing compounds under the hydrothermal process.

In the hydrothermal reactions with the use of $\mathrm{Ca}(\mathrm{OH})_{2}$ as the additive, the suppression of $\mathrm{CO}_{2}$ and the promotion of $\mathrm{H}_{2}$ generation are expected from the reactions which are expressed on Equation 3 and 4.

\section{Dioxins analysis}

\subsection{Dioxins}

The name "dioxins" is often used for the family of structurally and chemically related polychlorinated dibenzo para dioxins (PCDDs) and polychlorinated dibenzofurans (PCDFs). Certain dioxin-like polychlorinated biphenyls (PCBs) with similar toxic properties are also included under the term "dioxins". Some 419 types of dioxin-related compounds have been identified but only about 30 of these are considered to have significant toxicity, in which $\operatorname{TCDD}(2,3,7,8$ - tetrachlorodibenzo para dioxin) is the most toxic [32]. The formation 
mechanisms for them are not yet completely understood because of their complex production mechanisms [33]. Dioxins do have a damaging effect on human health and the environment [32,34], and 30 dioxins are known to have significant toxicity [32]. When biomass-containing chlorine is gasified in supercritical water, PCDDs, PCDFs and PCBs might be formed. In this study, dioxins in the liquid and solid phases produced through the hydrothermal reaction of chicken manure were determined.

\section{TEF and TEQ}

TEQ (toxic equivalent quantity) is total toxicity of dioxins contained in a sample and calculated by the Equation (7),

$$
\mathrm{TEQ}=\sum \mathrm{f}_{\mathrm{i}} \mathrm{g}_{\mathrm{i}}
$$

$f_{i}$ : toxic equivalency factor for ith dioxin (TEF, WHO 2006 [35])

$g_{i}$ : the abundance of $i$ th dioxin in the sample.

\subsection{Experimental procedure}

In order to examine the effect of the additive and the effect of temperature on dioxin formation in the chicken manure, the experiments were performed under six different conditions (Figure 4).

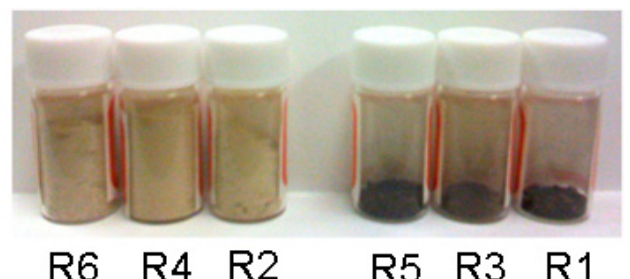

(a)

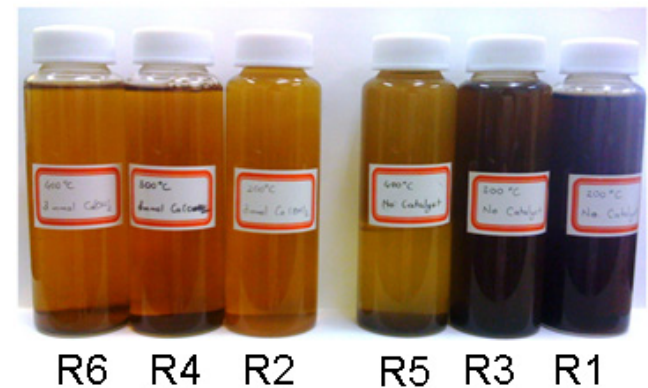

(b)

Figure 4. Photographs of solid (a) and liquid (b) samples from six different conditions. R1; without additive, $200{ }^{\circ} \mathrm{C}, \mathrm{R} 2 ; 3 \mathrm{mmol} \mathrm{Ca}(\mathrm{OH}) 2,200{ }^{\circ} \mathrm{C}, \mathrm{R} 3$; without additive, $300^{\circ} \mathrm{C}, \mathrm{R} 4 ; 3 \mathrm{mmol} \mathrm{Ca}(\mathrm{OH}) 2,300{ }^{\circ} \mathrm{C}$, R5; without additive, $400 \stackrel{\circ}{\circ}, \mathrm{R} 6 ; 3 \mathrm{mmol} \mathrm{Ca}(\mathrm{OH}) 2,400 \stackrel{\circ}{ } \mathrm{C}$. 
The samples produced under the various experimental conditions were separated into liquid and solid phases by filtration.

\section{Solid samples}

For determination of toxic equivalent quantity (TEQ) of each dioxin for the solid phase, the hydrothermal gasification experiment was carried out under the various conditions for the chicken manure. PCDDs and PCDFs were not detected. Three kinds of PCBs were only detected. These were T4CB\#77 (Fig. 5) (TEF=0.0001), P5CB\#118 (Fig. 6) (TEF=0.00003), and P5CB\#105 (Fig. 7) (TEF=0.00003).

The total TEQ values for solid samples were $0.00237,0.00357,0.00647,0.00196,0.00172$, and 0.00148 pgTEQg-1 $^{-1}$ for Run 1, 3, 5, 2, 4, and 6, respectively.

The highest total TEQ of 0.00647 pgTEQg $^{-1}$ was observed for the reaction temperature of $400^{\circ} \mathrm{C}$ without additive (Run 5). This level is well below the permitted Japanese level for solid residue (3000 pgTEQg $^{-1}$ ) [36].

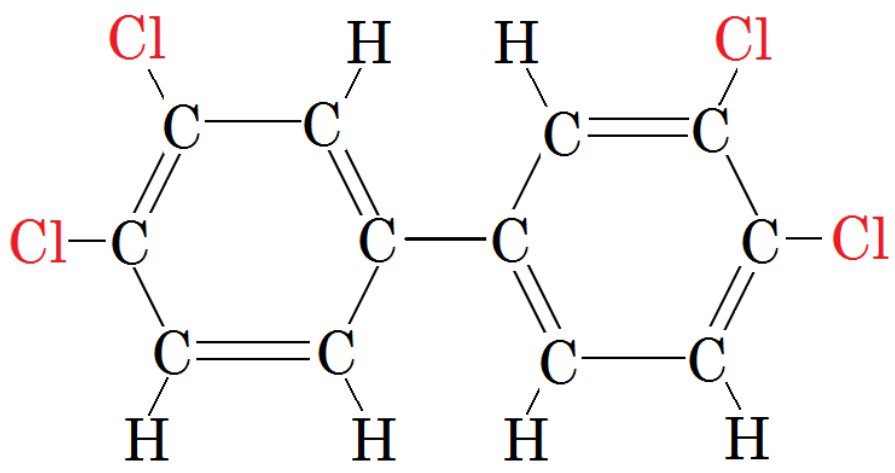

Figure 5. Chemical structure of T4CB\#77.

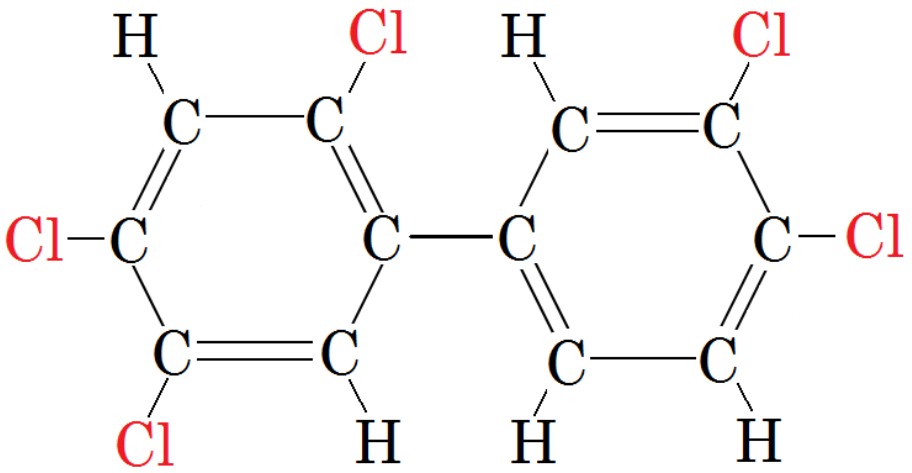

Figure 6. Chemical structure of P5CB\#118. 


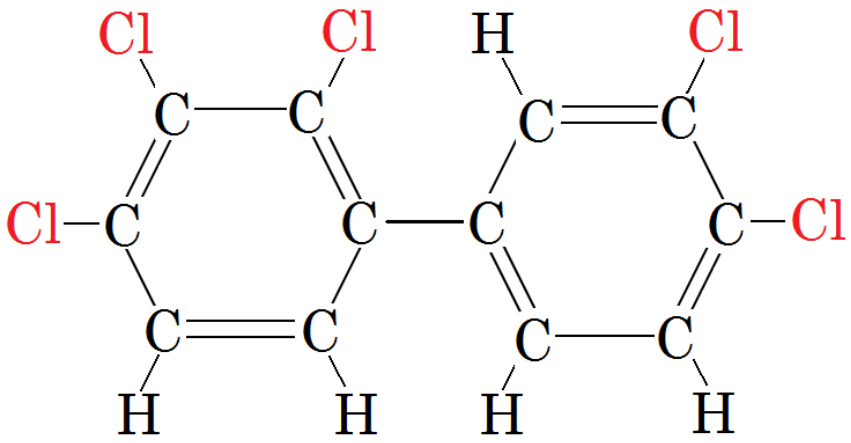

Figure 7. Chemical structure of P5CB\#105.

\section{Liquid samples}

In the case of the liquid phase products, PCDDs and PCDFs were not detected as they were in the case of the solid phase products. Two kinds of PCBs were detected (vs. three in the solid phase material). These were P5CB\#118 (TEF=0.00003) and P5CB\#105 (TEF=0.00003).

The total TEQ values were $0.00026,0.00054,0.00029,0.00023,0.00028$ and 0.00042 pgTEQL $^{-1}$ for Run 1, 3, 5, 2, 4, and 6, respectively.

With and without the additive, the total TEQs are nearly equal to the level of tap water. The results show that reaction temperature has little effect on the formation of dioxins. However, the addition of $\mathrm{Ca}(\mathrm{OH})_{2}$ increases the value of the TEQ at reaction temperatures of $300{ }^{\circ} \mathrm{C}$ and $400{ }^{\circ} \mathrm{C}$. The highest total TEQ measured was 0.00054 pgTEQL $^{-1}$, observed at the reaction temperature of $200{ }^{\circ} \mathrm{C}$ without the additive (Run 1). This total TEQ was well below the permitted Japanese limit for liquid residue (10 $\left.\mathrm{pgTEQL}^{-1}\right)$ [36].

\section{Conclusions}

Increase in energy consumption, limited energy capacity, environmental concerns related to fossil fuels, and security/safety concerns of some energy sources have all motivated the search for renewable energy sources.

A real biowaste, chicken manure, was used as an energy source and $\mathrm{Ca}(\mathrm{OH})_{2}$ was the most effective additive among the tested additive candidates for producing hydrogen in this study by the hydrothermal gasification process. Almost pure hydrogen gas could be obtained by adding $\mathrm{Ca}(\mathrm{OH})_{2}$ under supercritical conditions. It was found that the generation of hydrogen gas through hydrothermal gasification could be conducted without considering the toxicity of dioxins. Dioxins were detected, but they were far below the environmental regulation values. An added benefit found was that this process solves the problem of treatment of chicken manure while producing hydrogen.

This newly developed method of hydrothermal gasification of chicken manure is a promising method for producing hydrogen as a fuel and for disposing of the biowaste. 


\section{Author details}

Sevgihan Yildiz Bircan*

Department of Mechanical Science and Engineering, Graduate School of Engineering,

Nagoya University, Furo-cho, Chikusa-ku, Nagoya, Japan

Kozo Matsumoto

EcoTopia Science Institute, Nagoya University, Furo-cho, Chikusa-ku, Nagoya, Japan

Kuniyuki Kitagawa

EcoTopia Science Institute, Nagoya University, Furo-cho, Chikusa-ku, Nagoya, Japan

\section{References}

[1] US Census Bureau, BP (2002)

[2] M. King Hubbert, Nuclear energy and fossil fuels, Shell Development Company, Exploration and Production Research Division, Houston, Texas (1956)

[3] D. J. K. MacKay, Sustainable Energy-Without the hot air, UIT Cambridge, England (2009)

[4] L. Kong, G. Li, B. Zhang, W. He, H. Wang, Hydrogen production from biomass wastes by hydrothermal gasification, Energy Sources Part A, 30 (2008), Pages: 1166-1178

[5] D. B. Levin, H. Zhu, M. Beland, N. Cicek, B. E. Holbein, Potential for hydrogen and methane production from biomass residues in Canada, Bioresource Technology 98 (2007), Pages: 654-660

[6] Y. Calzavara, C. Joussot-Dubien, G. Boissonnet, S. Sarrade, Evaluation of biomass gasification in supercritical water process for hydrogen production, Energy Conversion and Management 46 (2005), Pages: 615-631

[7] W. Lijun, C.L. Weller, D.D. Jones and M.A. Hanna, 2008. Review: Contemporary issues in thermal gasification of biomass and its application to electricity and fuel production. Biomass Bioenergy 32, Issue 7, (2008), Pages: 573-581

[8] Y. Yurum, Hydrogen Energy System Production and Utilization of Hydrogen and Future Aspects : Proceedings of the NATO Advanced Study Institute, Akcay, Turkey, August 21-September 3 (1994)

[9] A. Kruse, Hydrothermal biomass gasification, J. of Supercritical Fluids 47 (2009), Pages: 391-399

[10] Y. Matsumura, T. Minowa, B. Potic, S. R. A. Kersten, W. Prins, W. P. MV. Swaaij, B. V. D. Beld, D. C. Elliott, G. G. Neuenschwander, A. Kruse, Jr. M. J. Antal, Biomass gasification in near- and super-critical water: Status and prospects (Review), Biomass and Bioenergy 29 (2005), Pages: 269-292

[11] A. Chu, D. S. Mavinic, H. G. Kelly, and C. Guarnaschelli, The influence of aeration and solids retention time on volatile fatty acid accumulation in thermophilic aerobic digestion of sludge. Environmental Technology 18 (1997), Pages: 731-738

\footnotetext{
${ }^{*}$ Corresponding Author
} 
[12] M. Momirlana, T. N. Veziroglu, The properties of hydrogen as fuel tomorrow in sustainable energy system for a cleaner planet, International Journal of Hydrogen Energy 30 (2005), Pages: 795-802

[13] M. Morimoto, H. Nakagawa, K. Miura, Hydrothermal extraction and hydrothermal gasification process for brown coal conversion, Fuel 87 (2008), Pages: 546-551

[14] M.J. Antal, S.G. Allen, D. Schulman, X. Xu, R.J. Divilio, Biomass gasification in supercritical water. Industrial \& Engineering Chemistry Research 39 (2000), Pages: 4040-53

[15] T. Yoshida, Y. Matsumura, Gasification of cellulose, xylan and lignin mixtures in supercritical water, Industrial \& Engineering Chemistry Research 40 (2001), Pages: 40:5469

[16] D. R. Edwards, T. C. Daniel, Environmental impacts of on-farm poultry waste disposal: A review Bioresource Technology 41 (1992), Pages: 9-33

[17] M. G. M. Berges, P. J. Crutzen, Estimates of global $\mathrm{N}_{2} \mathrm{O}$ emissions from cattle, pig and chicken manure, including a discussion of $\mathrm{CH} 4$ emissions, Journal of Atmospheric Chemistry 24 (1996), Pages: 241-269

[18] R. Khaleel, K. R. Reddy, M. R. Overcash, Transport of potential pollutants in runoff water from land areas receiving animal wastes: A review, Water Research 14 (1980), Pages: $421-436$.

[19] J. A. Onwudili and P. T. Williams. Role of sodium hydroxide in the production of hydrogen gas from the hydrothermal gasification of biomass, International Journal of Hydrogen Energy 34 (2009), Issue 14, Pages: 5645-5656

[20] R. C. Brown, Thermochemical Processing of Biomass: Conversion Into Fuels, Chemicals and Power (2011)

[21] S. Xiu, A. Shahbazi, V. Shirley, D. Cheng, Hydrothermal pyrolysis of swine manure to bio-oil: Effects of operating parameters on products yield and characterization of biooil, Journal of Analytical and Applied Pyrolysis 88 (2010), Pages: 73-79

[22] S. S. Toor, L. Rosendahl, A. Rudolf, Hydrothermal liquefaction of biomass: A review of subcritical water technologies, Energy 36 (2011), Pages: 2328-2342

[23] C.A.C. Sequeira, P.S.D. Brito, A.F. Mota, J.L. Carvalho, L.F.F.T.T.G. Rodrigues, D.M.F. Santos, D.B. Barrio, D.M. Justo, Fermentation, gasification and pyrolysis of carbonaceous residues towards usage in fuel cells, Energy Conversion and Management 48 (2007), Pages: 2203-2220

[24] A. Demirbas, Biorefineries: Current activities and future developments, Energy Conversion and Management 50 (2009), Pages: 2782-2801

[25] T. Yoshida, Y. Oshima, Y. Matsumura, Gasification of biomass model compounds and real biomass in supercritical water, Biomass and Bioenergy (2004), Volume: 26, Issue: 1, Pages: 71-78

[26] S. Yildiz Bircan, H. Kamoshita, R. Kanamori, Y. Ishida, K. Matsumoto, Y. Hasegawa, K. Kitagawa, Behavior of heteroatom compounds in hydrothermal gasification of biowaste for hydrogen production, Applied Energy Volume 88, Issue 12, December 2011, Pages: $4874-4878$ 
[27] S. Yildiz Bircan, R. Kanamori, Y. Hasegawa, K. Ohba, K. Matsumoto, K. Kitagawa GCMS ultra trace analysis of dioxins produced through hydrothermal gasification of biowastes, Microchemical Journal (2011) Volume 99, Issue 2, November 2011, Pages 556-560

[28] I. Nachamkin, C. M. Szymanski, M. J. Blaser, Campylobacter (2008), Page: 47

[29] R. Prabakaran, Good practices in planning and management of integrated commercial poultry production in South Asia (2003), Page: 88

[30] Z. Fanga, T. Minowa, C. Fang, Jr. R. L. Smith, H. Inomata, J. A. Kozinski, Catalytic hydrothermal gasification of cellulose and glucose, International Journal of Hydrogen energy 3, (2008), Pages: 981-990

[31] R. Kanamori, K. Matsumoto, K, Kitagawa, Behavior of phosphorus compounds in hydrothermal decomposition of biomass, World Renewable Energy Congress, Bangkok, Thailand (2009)

[32] World Health Organization (WHO), http://www.who.int/mediacentre/factsheets/fs225/en/

[33] T. Katami, A. Yasuhara, T. Okuda, T. Shibamoto, Formation of PCDDs, PCDFs, and Coplanar PCBs from Polyvinyl Chloride during Combustion in an Incinerator, Environmental Science \& Technology 36 (2002), Pages: 1320-1324.

[34] F. Coulston, F. Pocchiari, Accidental Exposure to Dioxins: Human Health Aspects, Academic Press, New York (1983)

[35] M. Van den Berg, L.S. Birnbaum, M. Denison, M. De Vito, W. Farland, M. Feeley, H. Fiedler, H. Håkansson, A. Hanberg, L. Haws, M. Rose, S. Safe, D. Schrenk, C. Tohyama, A. Tritscher, J. Tuomisto, M. Tysklind, N. Walker, R.E. Peterson, The 2005 World Health Organization reevaluation of human and mammalian toxic equivalency factors for dioxins and dioxin-like compounds, Toxicological Sciences 93 (2006), Pages: 223-241.

[36] Japan Ministry of the Environment, Overview on the treatment of POPs in Japan (2006) 